\title{
The common denominator
}

\author{
by Paul McKellips
}

In almost every equation, one can find a common denominator. Although it may seem a bit counterintuitive, even opposites have something in common.

Consider how the cultures of middle Eastern countries differ from those of the westernized world, full of war, violence and the oppression of women's rights. Yet during the Iraq war, I saw Arabic-speaking children mugging and posing for my cameras, holding out their hands for candy and wearing jerseys of their favorite world football (soccer) teams. Opposite cultures to be sure, but children the world over have something in common.

In Afghanistan, I trained 40 Pashtun students (all male). Each was predisposed to tell me why his education was superior to others and would free Afghanistan from its third-world, Flintstones-era rut. Opposite cultures to be sure, but students everywhere seem to have a common "I figured it out" aura, even if these particular Afghan men were oblivious to the complete absence of women in their classrooms.

Thomas Paine penned "Common Sense" as revolutionary fervor exploded. Online dating services match millions based on common traits. Republicans and Democrats have transformed politics into ultimate cage fighting events as partisan crowds cheer for blood while screaming for common ground. It would be, well, uncommon if our lives did not have at least some common denominators.

Before 2007, I had neither been in a lab animal facility nor given biomedical research much thought. For me, animal rights activism was the New Year's video featuring scantily clad PeTA models.

Scientists told me that animal research was still essential and lab animals were wellcared for. Activists told me that alternatives were far more reliable and lab animals were abused and tortured.

McKellips is Executive Vice President of the Foundation for Biomedical Research in Washington, DC.
I understood the passion of scientists and their focus on discovery and curing diseases. I understood (though disagreed with) activists who believed that old English property laws were antiquated and that animals should have rights, too.

Highly educated researchers were passionate about science. Highly extreme animal rights activists were passionate about anarchy. As I searched for common denominators among these polar opposite groups, I was hard-pressed to find anything they (we) had in common.

\section{The common denominator \\ was emerging, and the revelation was an epiphany of massively simple proportions.}

But I started to learn something from our monthly public opinion polling and focus groups with 100 people. I visited universities, CROs, biotech and pharmaceutical companies and, after each stump speech, I started to hear something from thousands of people out there on the circuit.

The common denominator was emerging, and the revelation was an epiphany of massively simple proportions: animal lovers.

As rural lifestyles migrated to the suburbs in the mid-twentieth century, animals moved out of the barn and into the bedroom. An animal that once had a role and a function on the farm soon had a diamond collar and a designer bed in the house.

We love our animals.

Whereas the animal rights extremists still love anarchy, the gentile animal opposition just loves animals.

The intellectual thinkers who sit atop the biomedical research 'org chart' analyze clues, solve puzzles and pontificate about the science behind the cures. They demand great care for lab animals because they know that happy, healthy, stress-free animals produce better data. Do they love animals? Maybe. But they definitely love their science. Drilling farther down the research 'org chart', the common denominator starts to emerge. I once thought that animal care staff, veterinary technicians and animal facility managers liked animals, loved science, needed jobs and wanted to be part of a team that found breakthroughs. All those things are still true. But I missed something. These people really-I mean really-love animals.

$\mathrm{Me}$ ? I love "Duke," my golden retriever, and I tolerate "Hunter," my son's gross lizard thing. But I don't gush, "Aw, he's so cute!" over mice, rats or other wild beasts. That's not the case with the lab animal folks. These people really_I mean really-love animals.

On one side, the extreme animal rights activists love their anti-capitalism more than they love their Auntie Kim's cats. On the other side, the principal investigators and Nobel scientists love their quest for knowledge, but I suspect they're more focused on the diseases killing humans and animals than on the types of toys that are best for enrichment.

That leaves two common populations: a wide swath of the public that opposes animal research, and the animal care community that takes care of lab animals.

The common denominator? You're both animal lovers.

When we conduct 100-person focus groups, the participants don't ask us for poster presentations, the latest scientific data or how long until we have a cure. They want to know how well lab animals are cared for; whether they are nourished and enriched; whether someone plays with them; and whether are they loved.

So the next time you struggle to tell someone where you work and what you do, remember to start with the common denominator...love. No one is more qualified to work in a lab animal facility than a warm-hearted person who, at the core, is an animal lover. 